\title{
Balamuthia mandrillaris
}

National Cancer Institute

\section{Source}

National Cancer Institute. Balamuthia mandrillaris. NCI Thesaurus. Code C122184.

A species of free-living amoeba in the family Balamuthiidae. B. mandrillaris is the causative agent of granulomatous amoebic encephalitis. It was isolated from the brain of a captive baboon and has not been definitively isolated in nature. 